\title{
Estética, liberdade e reflexividade: repensando Bourdieu
}

\section{Amarildo Malvezzi*}

\section{Resumo}

A sociologia de Pierre Bourdieu tem sido constantemente acusada de determinista e reprodutivista, principalmente devido ao modo pelo qual o conceito de habitus foi teorizado. Por essa razão, tem sido comum o esforço de seus leitores para resgatar resíduos e margens de liberdade em suas obras. Nesse contexto, a reflexividade aparece como princípio básico para uma leitura não determinista nem reprodutivista do pensamento bourdieusiano. Nessa investida, ao menos três possibilidades teóricas têm sido aventadas: a reflexividade sociológica, o conceito de hysteresis e a existência de habitus clivados. Todavia, o presente artigo parte das limitações e aponta para uma via ainda pouco explorada: a dimensão estética. Duas vias são fundamentais: (i) o ofício do artista; (ii) a experiência estética. A partir de ambas, buscar-se-á pensar a relação entre habitus, estética, liberdade e reflexividade.

Palavras-chave: Habitus, estética, gosto, artista, reflexividade.

* Universidade Federal de Pernambuco, Recife, PE, Brasil. 


\section{Aesthetics, freedom and reflexivity: rethinking Bourdieu} Abstract

Pierre Bourdieu's sociology has been consistently accused of being deterministic and reproductivist, mainly because of the way in which the concept of habitus was theorized. For this reason, his readers have often striven to retrieve vestiges and margins of freedom in his works. In this context, reflexivity appears as a basic principle for a non-deterministic nor reproductivist reading of the Bourdieusian thinking. In this attempt, at least three theoretical possibilities have been proposed: sociological reflexivity, the concept of hysteresis and the existence of cleaved habitus. However, the present article starts from the limitations of such vestiges and points to a still unexplored path: the aesthetic dimension. Two paths will be fundamental: (i) the craft of the artist; (ii) the aesthetic experience. Based on both, we will try to think about the relationship between habitus, aesthetics, freedom and reflexivity.

Keywords: Habitus, aesthetics, taste, artist, reflexivity.

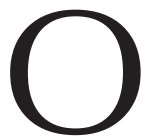

legado sociológico de Pierre Bourdieu é irredutível à dimensão epistemológica. Sendo também político, é, portanto, indissociavelmente teórico e crítico. As inovações teóricometodológicas transformam a própria linguagem das teorias críticas, possibilitando novas leituras da vida social, especialmente aquelas dedicadas às dinâmicas opressivo-emancipatórias. Sua consagração intelectual devese, igual e inegavelmente, ao domínio do poder simbólico, isto é, ao nexo entre saber e poder. O mesmo é dizer que a vida intelectual de Bourdieu importa não apenas pela dimensão cognitiva, mas também por sua disposição subjetiva desviante e transgressora. Seu projeto sociológico, fundado a partir da dupla recusa à falsa antinomia objetivismo-subjetivismo, manifesta-se em sua disposição intelectual, que o leva à dupla resistência a Lévi-Strauss e a Sartre, recusando submeter-se a e a identificar-se com autoridades intelectuais já reconhecidas.

A íntima ligação entre epistemologia e política no projeto fundador de uma teoria das práticas reverbera no próprio discurso de boa parte de seus críticos (Alexander, 1995; Jenkins, 1982; Olson, 1995). Paradoxalmente, o 
refinamento teórico-analítico, isto é, o desenvolvimento de instrumentos intelectuais voltados à investigação, captura e interpretação de evidências da não liberdade nas práticas sociais e mesmo nas subjetividades, tê-lo-ia tornado inapto ao reconhecimento e à compreensão da liberdade, contradizendo a própria dialética bourdieusiana que visava ampliar a liberdade a partir do (re)conhecimento de formas inconscientes e infrasensíveis de dominação (Boltanski, 2011) .

A irônica pintura esboçada por Boltanski (2011), segundo a qual a razão teórica de Bourdieu padeceria de uma enfermidade crônica, submetendo-o a uma obsessão pela dominação que o faria perder o tato para a liberdade, apenas leva ao extremo o consenso constituído pelos críticos menos flexíveis de Bourdieu: a falha genética de seu sistema teórico condenaria os agentes sociais a um estado de heteronomia - afinal, se a reflexividade é considerada como princípio básico para se pensar a liberdade dentro de seu sistema, ela encontra-se quase interditada na vida cotidiana dos indivíduos (Jenkins, 1982; Knafo, 2016; Hilgers, 2009; Peters, 2013). Eis, novamente, o encontro entre epistemologia e política. A falha teórica imporia um fracasso a seu regime de crítica social. Na hipótese da impossibilidade da reflexividade, a liberdade tornar-se-ia impossível e a dominação se tornaria total, ao mesmo tempo mais íntima e universal. A gênese desse obscurecimento político (a suposta impossibilidade da reflexividade e todas as suas consequências nefastas) é essencialmente teórica, enraizada que está na própria concepção do habitus que, no projeto de Bourdieu, seria a ferramenta essencial na promoção da transcendência em relação à falsa antinomia objetivismo-subjetivismo, por permitir enxergar, por um lado, o papel dos condicionamentos sociais e, por outro, o papel ativo-construtivo dos agentes.

A presente investigação assemelha-se a um ensaio, àquilo que Adorno (2003) concebia como forma de experimento intelectual, tentativa de apontar para novas perspectivas, sem pretender - de forma alguma esgotar o assunto ou higienizar-se de todas as possíveis contradições e limitações. Tem como ponto de partida o diagnóstico dos críticos de 
Bourdieu e visa problematizar o veredicto segundo o qual este autor seria incapaz de rastrear a liberdade (ligada à dimensão crítica de seu ofício), principalmente por suprimir a reflexividade (deficiência enraizada em sua matriz teórica). Será defendido que, apesar dos extensos argumentos da crítica, é possível reconhecer espaços para a reflexividade e a liberdade na teoria bourdieusiana, mas sem ignorar suas limitações - o que imporá a necessidade de se pensar novos caminhos. A dimensão estética aparecerá como alternativa, espaço privilegiado para se relacionar habitus, liberdade e reflexividade, por dois caminhos: (i) a partir do esboço de um habitus aestheticus, ligado ao modo de ser dos artistas puros; (ii) por meio do gosto, elemento central na análise bourdieusiana da experiência estética.

\section{Quadro clínico impreciso}

No que diz respeito à teoria sociológica bourdieusiana, é lugar comum remeter sua elaboração teórica, consumada em uma teoria das práticas sociais, ao desejo de superar a parcialidade dos modos de conhecimento objetivista (incapaz de pensar os agentes sociais em sua dimensão ativa e construtiva) e subjetivista (que desconsidera o papel constitutivo dos condicionamentos sociais). Resulta, assim, que a síntese almejada por Bourdieu buscava instituir uma autêntica dialética entre os condicionamentos sociais (o papel estruturante das estruturas sociais) e as disposições práticas dos agentes (papel construtivo dos agentes). De forma extremamente abstrata, pode-se dizer que a intenção de seu projeto seria capturar o movimento permanente de conversão da objetividade em subjetividade e da subjetividade em objetividade, através de uma compreensão da história como dividida em duas formas: a objetiva, resultante do processo de exteriorização das disposições individuais, que é a própria subjetividade tornada estrutura; e a subjetiva, percebida como processo de conversão das estruturas sociais em sujeito, das condições de existência em uma estrutura subjetiva. A engenharia teórica de Bourdieu necessitava de um elemento teórico-investigativo capaz de posicionar o agente exatamente 
como ponte, lugar no qual as estruturas sociais poderiam ser convertidas, primeiramente, em subjetividades, e que, essa subjetividade socialmente produzida, pudesse ser posteriormente construtora das estruturas sociais. O habitus, pensado nesse movimento, é central por responder à dimensão teórica do sistema bourdieusiano na qual o agente - ora exilado pelos estruturalistas, ora fetichizado pela fenomenologia - seria corretamente posicionado na teoria social, reconhecendo o papel inventivo-construtor, ainda que socialmente condicionado e limitado.

Independentemente da complexa e sofisticada teorização do habitus, bem como de sua sedutora promessa de superação das deficiências inerentes às diversas matrizes sociológicas, diversos críticos (Alexander, 1995; Jenkins, 1982; Peters, 2013) de Bourdieu reconheceram, na própria concepção do habitus, deficiências graves que resultaram em um quadro clínico pessimista: a impossibilidade de se ascender à reflexividade na vida prática, cuja principal consequência seria a impossibilidade da resistência, da crítica, da autonomia e da liberdade. Esse diagnóstico pode ser (re)constituído a partir de cinco aspectos fundamentais: (1) o primado da pré-reflexividade na teorização do habitus - resultante da tentativa de se afastar da filosofia da consciência por ser demasiadamente intelectualista - centralizou as dimensões corporais e os saberes práticos como princípios fundamentais da vida societária, culminando em uma subteorização da reflexividade e do papel da consciência; (2) a concepção do habitus como um sistema autônomo em relação aos agentes, isto é, a visão segundo a qual ele funciona como princípio gerador de todas as práticas (sendo, inclusive, constituinte da própria vida psicológica) sem que os agentes tenham consciência de seu papel determinante e estruturante subjetiva e socialmente; (3) a redução da subjetividade ao habitus, concebido como princípio único a partir do qual são geradas as mais diversas práticas, produzindo uma visão da identidade subjetiva como homogênea e, por isso, condenada à reprodução das estruturas sociais incorporadas, agora existentes e atuantes como agentes sociais; (4) a inércia intrínseca ao habitus, que concede peso maior às experiências passadas em relação às futuras, gerando uma 
lógica prática mais automática, mecânica, reprodutora; e (5) a própria fundamentação bourdieusiana do objeto sociológico como cumplicidade ontológica, ou seja, a busca pelas condições de possibilidade da própria vida social, proveniente, em sua visão, do encontro harmonioso, coerente e ajustado de uma história subjetiva (pertencente à esfera das disposições subjetivas práticas) e a história objetiva (ligada às estruturas sociais), culminando em uma compreensão da vida social a partir da integração bem-sucedida entre as disposições incorporadas e as demandas societárias contextualmente localizadas. O quadro clínico, como se pôde retraçar, agrega uma diversidade de constatações que radicalizam o diagnóstico segundo o qual é improvável encontrar espaço para a reflexividade/liberdade na teoria bourdieusiana, o que a leva a ser pensada sob a lógica de um reprodutivismo ou neoobjetivismo.

Tal visão, que pode atingir caracterizações radicais, embora esteja embasada na própria fundamentação teórica de Bourdieu, encontra pelo menos três refutações significativas: (1) a declarada e reconhecida existência da reflexividade no próprio ofício do sociólogo, possibilitada por uma ruptura epistemológico-social da razão teórica com a lógica da prática, que é concebida à luz de uma temporalidade irreversível e inadiável, bem como por uma plena imersão dos agentes sociais, o que posicionaria a consciência em um segundo plano - assim sendo, é pela instituição de uma relação teórico-cognitiva com o mundo das práticas, possível graças à existência de um campo científico que se emancipa da lógica da prática, instaurando um movimento de clarificação que vai da inconsciência à consciência, superando a amnésia histórico-coletiva (Bourdieu et al., 2015); (2) a hysteresis, concebida como ruptura da cumplicidade ontológica entre indivíduo e sociedade, a partir da incongruência entre as disposições práticas subjetivas e as demandas contextuais objetivas, impele os agentes à reflexividade a partir do momento em que o desajuste ontológico-estrutural impossibilita a realização de práticas automáticas e não conscientes, exigindo, pelo contrário, a atuação de uma consciência-reflexiva para que se realize a atualização-adaptação dos saberes práticos antigos-defasados às novas 
circunstâncias (Bourdieu, 2013); e (3) a existência de habitus clivados, isto é, subjetividades constituídas por princípios de ação divergentes, caracterizados por valores e vontades oblíquos, contraditórios, inconciliáveis, provenientes da conversão de distintas condições de existência em princípios de ação divergentes, induzindo os agentes à reflexividade devido à impossibilidade de agirem de modo pré-reflexivo, dada a necessidade de, a cada instante, realizarem escolhas práticas entre opções divergentes/excludentes (Bourdieu, 2001).

As três vias, no entanto, não estão abertas a todos os agentes, portanto, são passíveis de críticas devido às limitações intrínsecas: (a) a reflexividade sociológica é, dentro da teoria bourdieusiana, quase um monopólio do campo sociológico, isto é, de um espaço social delimitado no qual seus integrantes, submetidos a seus princípios, podem se ocupar de um ofício sob circunstâncias estruturais que fornecem as condições necessárias para a promoção e proteção da reflexividade como uma virtude necessária; (b) a reflexividade proveniente da hysteresis, por sua vez, possui um caráter acidental (inesperado desajuste entre disposições e demandas), efêmero e instrumental (a reflexividade é mobilizada como ferramenta prática destinada à restauração da cumplicidade ontológica entre indivíduo e sociedade, sendo abandonada posteriormente), podendo ser mais bem caracterizada como um sintoma do desajuste ontológico-estrutural entre indivíduo e sociedade do que como verdadeira conquista de liberdade e autonomia - se há espaço para reflexividade e agência, é de ordem racionalinstrumental-adaptativa; e (c) já a reflexividade ligada à existência de habitus clivados tem como fragilidade sua dimensão intrinsecamente negativa; afinal, ela depende de uma condição subjetiva marcada pelo dilaceramento, pelo sofrimento existencial presente em individualidades estraçalhadas, impondo a questão de se a reflexividade pode ser positivamente ligada a uma prazerosa liberdade ou se, ao contrário, melhor conecta-se a formas históricas de sofrimento subjetivo, típicas, inclusive, das sociedades plurais/ pós-tradicionais. 
Apesar de ser possível contradizer o veredicto fatalista produzido pelos críticos de Bourdieu, percebe-se que as principais refutações padecem de limitações. A parcialidade das alternativas impele à reflexão acerca da possibilidade de se resgatarem espaços práticos nos quais a reflexividade seja possível, transcendendo o monopólio dos intelectuais ligados ao campo sociológico; o caráter acidental, efêmero e instrumental da reflexividade localizada no desajuste típico da hysteresis; o sofrimento existencial subjacente às clivagens. $\mathrm{O}$ argumento a ser desenvolvido é o de que há, na própria produção de Bourdieu, um vasto espaço mal explorado: a dimensão estética. Tanto o campo artístico quanto o gosto (em sentido estético), à semelhança do campo sociológico e da razão teórica, possibilitam uma via produtiva para se buscar a liberdade e a reflexividade.

\section{A Estética não é marginal para a sociologia reflexiva}

O deslocamento do debate para a dimensão estética, para exatamente aí (re)pensar a teoria bourdieusiana, tem como esperança a transcendência dos elementos limitadores contidos nas alternativas expostas: extrapolar o ofício do sociólogo inserido em um campo ligado à racionalidade científica; escapar ao caráter arbitrário, efêmero e instrumental da hysteresis, ampliando as condições de possibilidade de emergência da reflexividade em contextos diversos; e pensar margens de liberdade e reflexividade ligadas a uma (in) determinação do habitus não mais por uma ótica negativa.

Essa transição, todavia, não é abrupta. Como defende Luc Ferry (1994), o reino da estética é um lugar privilegiado para se pensar a subjetividade, especialmente à luz da tensão entre indivíduo e sociedade. Quanto a Bourdieu, o título a ele atribuído de um dos fundadores da recente Sociologia do Gosto não é injustificado. A categoria do gosto é central em suas investigações, especialmente aquelas ligadas ao campo da arte e aos estilos de vida. Ressalte-se que a centralidade do gosto não é acidental. Há 
uma proximidade lógica entre o gosto (em seu sentido estético ${ }^{1}$, tal como pensado pelos filósofos) e o habitus: por essa razão, este aparece como constructo teórico privilegiado. Apontam para uma inteligência de ordem prática, operando a distância da consciência, associados mais à dimensão corporal do que à dimensão racional-teórica. Assim como o habitus coloca em primeiro plano a lógica da prática, em que a consciência e a reflexividade são recursos latentes, o gosto aparece como uma abertura importante para se acessar a própria subjetividade. Por essa razão, a conversão do gosto em um objeto sociológico, para Wacquant (2011), é homóloga à conversão do suicídio em objeto de investigação por Durkheim: em ambos os casos, mobiliza-se o conhecimento sociológico para resgatar a dimensão históricosocial daquilo que aparece propriedade natural da vida íntima das pessoas.

Além de a categoria estética do gosto ter uma acentuada afinidade lógica e teórica com a do habitus, é válido lembrar que o contexto histórico aponta para um fluxo histórico interessante: se em um primeiro momento o gosto foi central aos discursos estéticos, especialmente os do século XVIII, exatamente no século do nascimento da Estética, por outro, o gosto tornou-se progressivamente desprestigiado, tanto no discurso filosófico quanto no mundo das artes². Essa tendência, todavia, é complementada por outra: a queda do gosto, no âmbito filosófico e artístico, é sucedida por sua ascensão junto à própria estetização da vida cotidiana, associada à aparição de uma indústria cultural que opera uma instrumentalização da estética na produção e consumo de mercadorias, concebidas sob a forma de espetáculos. Esse duplo movimento, de centralidade e declínio

${ }^{1} \mathrm{O}$ gosto de que se trata, aqui, não diz respeito ao sentido literal do paladar, mas, mais especificamente, a seu sentido estético, que é produto de uma conversão metafórica do modo de funcionamento do paladar para o modo de relacionamento com objetos estéticos, unindo percepção (dimensão sensível) e julgamento (dimensão valorativa), através de um modo de funcionamento veloz, não racional, autônomo. Válido lembrar, além disso, que, embora a metáfora do gosto sirva tão bem à estética, não há espaço para ela no sistema das artes, como alegam Kant, Hegel e Adorno.

${ }^{2} \mathrm{O}$ movimento de autonomia da arte implicava a ruptura da relação entre artista e público, conduzindo, então, a um abandono de uma estética voltada para a produção de prazer e de acordo com o público. 
na filosofia, e de ascensão na vida cotidiana, coloca em questão o fato de que a Sociologia do Gosto aparece exatamente no momento em que a estetização do cotidiano se torna possível e a necessidade de distinguir arte e realidade não poderia mais se dar por via de uma estética do gosto (Danto, 2015). O gosto aparece na vida cotidiana como central, ligado a três princípios fundamentais: o individualismo, o hedonismo e o respeito à diferença. O gosto, no interior de sociedades pós-tradicionais, isto é, nas quais inexiste um horizonte moral e cognitivo hegemônico/universal, aparece como bússola a partir da qual os indivíduos podem guiar suas existências (Ferry, 1994). A ética da autenticidade - de ser verdadeiro consigo próprio e estar em acordo consigo próprio - pode ser mensurada pelo próprio gosto: o prazer subjetivo torna manifesto o acordo consigo próprio, é cifra dessa identidade consigo mesmo ${ }^{3}$.

Independentemente da gramática teórica, o contexto atual (seja ele considerado como pluralista, pós-tradicional ou pós-moderno) aponta para o fato de que inexiste uma cultura única, hegemônica e universal. A pulverização em segmentos coloca, então, a sociologia da cultura preocupada com os estilos de vida - isto é, aborda-se a cultura por uma ótica mais prática, mas, principalmente, mais particularizada. E, novamente, o gosto resplandece: ele é a unidade básica do estilo de vida, o princípio básico de todas as escolhas, é constituinte. A abertura contemporânea na construção da própria identidade a partir de um gerenciamento da própria existência, segundo a ótica política, exprime uma forma de autogoverno, isto é, de liberdade e autonomia - e o gosto aparece como termômetro que permitiria aos indivíduos pensar em que medida determinadas práticas e valores the aprazem ou não.

\footnotetext{
${ }^{3}$ Evidentemente, nesse caso, por uma ótica crítica, cabe perguntar se não é exatamente por meio dessa lógica de identidade consigo próprio, a partir de cifras de prazer, que o indivíduo pode, (per)seguindo esse princípio, acabar por reproduzir a própria dominação, como é apontado por Adorno e Horkheimer (1985) e Eagleton (1993), a partir do momento em que se pensa a possibilidade de o gosto ser um instrumento internalizado de opressão, dominação e reprodução social.
} 
E, além da afinidade entre gosto e habitus e do atual pano de fundo histórico, há um indício forte que aponta para o argumento central: a dimensão estética não é marginal à sociologia reflexiva. O post-scriptum de As regras da arte é um manifesto intitulado "Por um corporativismo do universal", no qual Bourdieu (1996) busca construir uma aliança entre intelectuais de diversos campos simbólicos, especialmente os artistas (agentes da dimensão estética) e cientistas (agentes da dimensão científica). A figura do intelectual, para Bourdieu, remete à existência de um determinado tipo de habitus, produto de uma história coletiva e que encarnaria, na modernidade, o poder da crítica. Ao se debruçar sobre esse manifesto, é possível compreender que a estética não é marginal à sociologia reflexiva, afinal, a reflexividade sociológica tinha dois objetivos essenciais para Bourdieu: um, de diagnosticar a não liberdade e outro de reconhecer as condições de possibilidade da liberdade e torná-la universal. Por essa razão, é um "corporativismo do universal", afinal, trata-se de uma aliança entre figuras privilegiadas, que desfrutam de condições de existência que tornam possíveis tanto a liberdade quanto a crítica (possível exatamente pela existência de uma reflexividade). Nesse sentido, há uma homologia entre ciência e arte, para Bourdieu, haja vista que existe um grau de semelhança entre os cientistas e os artistas. Em ambos os casos, são intelectuais, ou seja, indivíduos capazes de mobilizar o poder simbólico na contramão da dominação e da opressão, fazendo-nos compreender o enraizamento da sociologia reflexiva na tradição iluminista. E, se para Bourdieu a dimensão estética aparece como fundamental, e lá o gosto é inserido como categoria central, cabe investigar como é possível encontrar margens de liberdade e reflexividade na dimensão estética.

Para isso, será abordado como o artista - entendido como intelectual convocado por Bourdieu para integrar seu movimento coletivo de resistência e crítica - é capaz de mobilizar o poder simbólico no sentido de produzir resistência e crítica, ou seja, como seria possível rastrear a reflexividade no ofício do artista? Posteriormente, caberá pensar como o público poderia, 
no interior de experiências estéticas, ascender à reflexividade ou conquistar mais margens de liberdade.

\section{Esboço de um habitus aestheticus}

Bourdieu (2011) considera a dimensão estética como espaço simbólico privilegiado em que se produz a imagem do humano, isto é, sua distância e superioridade em relação à animalidade. Afinal, se o que constitui o humano é o corte entre cultura e natureza, a ascese e a sublimação seriam os aspectos essenciais que atestariam o poder de neutralizar a natureza e conquistar margens de liberdade ${ }^{4}$. Ora, é na dimensão estética que a capacidade de ascese e sublimação se revelam mais espiritualizadas, como se pode enxergar no prazer estético, que seria "símbolo de excelência moral" (Bourdieu, 2011, p. 452). O discurso estético - como aparece nas produções de Kant, Schiller e Adorno - estaria vinculado à instituição de uma distinção ontológica entre o autêntico humano e o mero animal, tanto que Bourdieu (2011, p. 17) afirma ser o gosto "a manifestação suprema do discernimento que, pela reconciliação do entendimento com a sensibilidade [...] define o homem na acepção plena do termo".

A ênfase em uma autêntica humanidade revelada pela estética e pelo gosto tem a ver com o fato de que o simples corte entre cultura e natureza, tão caro à "ciência do homem", não implica uma condição de existência plenamente autônoma. Basta que se lembre o fato de que o habitus - cultura feito corpo - é uma segunda natureza, podendo, então, a dimensão simbólica ser mobilizada como um instrumento de dominação e opressão. A distinção entre humanidade e animalidade não encerra, de uma vez por todas, a questão da condição humana. O processo de aquisição cultural - a própria instituição de um habitus a partir da subjetivação - é intrinsecamente violento, visto que um determinado arbitrário cultural

${ }^{4} \mathrm{Em}$ A Distinção, Bourdieu afirma que "a capacidade de sublimação define o homem verdadeiramente humano" (2011, p.14). Bourdieu chega a afirmar que os discursos estéticos operam como uma espécie de monopólio da humanidade" (2011, p. 454). 
passa a operar como um mecanismo inconsciente, determinando o modo de ser dos indivíduos.

O interessante, todavia, é que todo o problema da crítica, que pensa o habitus como determinista, não condiz com a compreensão de Bourdieu acerca do artista. De modo implícito, Bourdieu esboça - de modo disperso e sem pretensão de universalização - uma espécie de habitus aestheticus ${ }^{\mathbf{5}}$. Seguiremos a (re)construção ideal-típica desse habitus a partir de três vias, recuperando (a) o estilo de vida do artista e seu perfil psicológico; (b) as condições estruturais de seu ofício, que nos remeterão ao campo artístico autônomo; e (c) o ofício do artista, especificamente, o trabalho sobre a forma. O objetivo é duplo: visa à recuperação de indícios de liberdade e de reflexividade, com base nesse habitus aestheticus, obtido a partir do artista.

\section{O modo de ser do artista: não seriedade e ambivalência}

Em relação às dimensões psíquica e prática associadas aos artistas, Bourdieu as concebe à luz de duas características essenciais: o caráter leviano e o espírito ambivalente, fundamentais para uma relação estética com a existência, que culminam em uma forma de estetismo.

A não seriedade remete a uma condição subjetiva de incapacidade de levar o real a sério, o que quer dizer incapacidade de identificar-se com determinado arbitrário, com determinada illusio. Se a illusio diz respeito às disposições psicológicas necessárias para que determinado indivíduo esteja visceralmente ligado a uma ordem simbólica (é tanto crença quanto desejo), a não seriedade dos artistas, aos olhos de Bourdieu, é interpretada como uma forma de resistência - o que o leva a associar o modo de ser dos artistas ao espírito infantil e à revolta adolescente. Em ambos os casos, trata-se de uma recusa fundamental: a de não se submeter ao processo de envelhecimento social, isto é, fazer escolhas e sacrifícios, assumir um papel fixo, uma identidade/trajetória/destino social. A imagem do adolescente é

${ }^{5}$ Ressalte-se que essa caracterização é construída a partir da visão bourdieusiana do artista puro, que é tanto construtor de um campo de arte autônomo quanto condicionado por esse espaço prático. 
representativa da última etapa social diante da qual os indivíduos usufruem de um universo de possibilidades abrangente.

A pobre identificação com o universo social condiciona a existência de um espírito ambivalente. O artista é, para Bourdieu, uma figura histórica incapaz de se identificar plenamente com qualquer papel/posição/trajetória social. É concebido como um ser flutuante, capaz de oscilar entre os diversos polos da vida social, como transparece no próprio fato de que o artista puro é incapaz de filiar-se integralmente aos anseios do povo - que vive em uma condição precária - ou às ideias das elites - filisteus. A ambivalência, à luz da teoria do habitus, significa internalização de uma condição objetiva (in)determinada, cujo resultado seria a construção de uma subjetividade ambivalente, incapaz de identificar-se com o que quer que seja, mas, ao mesmo tempo, aquele que não é determinado por coisa alguma.

Essa caracterização da ambivalência aproxima-se do habitus clivado, mas com uma interessante distinção: ele é marcado pela atuação ativa de distintos princípios de existência, ao passo que a ambivalência revela uma indiferença existencial, um alheamento, exatamente por causa da pouca adesão às illusios. De um lado, haveria ímpetos contraditórios, gerando uma indecisão dilacerante; de outro, neutralidade e indiferença, um movimento inconsequente entre as possibilidades.

Ao levar ao extremo essa condição, o artista levaria um estilo de vida ligado a um estetismo, impondo os princípios estéticos acima dos éticos, o mundo da arte (universo da não seriedade) sobre o mundo real. E é exatamente na instituição de um modo de vida alternativo e particular que Bourdieu percebe a liberdade do artista. O estetismo é uma ruptura social que neutraliza o arbitrário cultural, rompendo a naturalização das formas de vida em seu sentido mais amplo. Em As regras da arte, Bourdieu (1996, p. 49) afirma que "a illusio romanesca, que, em suas formas mais radicais, pode chegar [...] a abolir a completa fronteira entre arte e ficção encontra seu princípio na experiência da realidade como illusio". A arte, então, seria o lugar privilegiado para se "lembrar que a realidade com a qual comparamos todas as ficções não é mais do que o referente reconhecido 
de uma ilusão (quase) universalmente partilhada" (Bourdieu, 1996, p. 50). A ficção opõe-se ao caráter reificado da vida social (determinista e fatalista), restituindo o caráter histórico das formas de vida, isto é, a liberdade ligada à possiblidade de ser-assim-ou-de-outra-forma.

\section{Condições estruturais do ofício: autonomia, anomia e liberdade}

No início de sua Teoria Estética, Theodor Adorno constrói discursivamente uma contradição histórico-ontológica da arte. Com a autonomização da esfera da arte em relação ao mundo prático - a arte não mais estava submissa a funções sociais -, paradoxalmente, a liberdade por ela conquistada lançou as obras de arte em um estado de incerteza, afinal, havia-se solapado os fundamentos sociais de sua existência (Adorno, 1970). Emancipada, a arte teria perdido seu sentido no mundo, e a abertura à liberdade de ser feita de infinitas formas não compensaria o estado de incerteza que isso gerou.

A arte pura, supostamente livre de toda referência externa, e impelida à construção do novo pela recusa de qualquer modelo pré-fabricado que pudesse manchar a autonomia e liberdade do artista, ao elevar-se ao status de norma do campo de produção, também teria gerado, segundo Bourdieu (1996), um estado de anomia estética: tudo é possível, embora nem tudo possua valor equivalente. Se, para Adorno (1970), o estado anômico geraria incerteza quanto ao sentido da arte, ao direito de sua existência, para Bourdieu (1996), ao contrário, a liberdade estética concederia um maior papel ao artista como produtor simbólico. Sua função transcenderia a de mero "criador de belas aparências", tornando-se, inclusive, o agente histórico capaz de transformar os esquemas de percepção e apreciação da arte.

A anomia estética seria a conversão da liberdade estética em um estado no qual inexiste uma norma única e exclusiva regulamentando a produção. Com isso, emerge uma pluralidade de formas possíveis de se fazer arte - como demonstraram as diversas vanguardas. $\mathrm{O}$ artista, então, passa a desfrutar de uma margem de liberdade jamais vista. Todavia, o campo 
de produção simbólica não seria homogêneo, isto é, nem toda produção partilharia do privilégio de uma liberdade estética concreta - Bourdieu afirma que o campo de produção simbólica se divide entre aqueles que produzem arte de acordo com interesses majoritariamente materiais e aqueles que, recusando o prestígio econômico cujo retorno é mais imediato e socialmente valorizado, são favoráveis a uma lógica desinteressada, mas aberta ao reconhecimento por parte dos outros agentes do campo, por meio de critérios mais particulares. A arte pura, ao se opor à arte social e à arte burguesa, à missão social e à função social, seguiria sua própria lógica ${ }^{6}$.

A consequência disso é que, se não há mais uma única forma de se produzir arte, nem mesmo um conceito universal do que ela seja, abrese margem para liberdade do artista em sua produção - e é exatamente no trabalho sobre a forma, possível exatamente devido a essas condições estruturais, que se pode encontrar, em Bourdieu, uma relação entre o ofício de artista e uma forma de reflexividade.

\section{O trabalho sobre a forma: objetivação e reflexividade}

Subjacente à análise sociológica das regras do campo da arte, há um argumento que me parece fundamental para a relação entre arte e reflexividade. O fragmento abaixo, extraído de As regras da arte, condensa de modo vigoroso três importantes postulados: (i) a arte é um discurso sobre o mundo (o que a liga à esfera do conhecimento); (ii) existe uma forma de objetivação das estruturas sociais inscrita no fazer artístico (processo que, para Bourdieu, leva da in-consciência à consciência); e (iii) o trabalho formal do artista é o fundamento prático tanto da objetivação das estruturas sociais quanto da produção de um discurso sobre o mundo (o ofício do artista é uma prática social privilegiada para Bourdieu).

${ }^{6} \mathrm{~A}$ constituição de um campo autônomo torna-se condição de possibilidade de práticas artísticas livres; então, embora práticas não deterministas sejam possíveis, elas pressupõem condições sociais de possibilidade, ou seja, precisam ser conquistadas historicamente. Ao resgatar a gênese histórica do campo de arte pura, Bourdieu esmiúça os fundamentos de uma liberdade intelectual possível dentro da dimensão estética. 
O que é, com efeito, esse discurso que fala do mundo (social ou psicológico) como se não falasse dele; que não pode falar desse mundo senão com a condição de que fale dele apenas como se não falasse, ou seja, em uma forma que opera, para o autor e o leitor, uma denegação [...] do que exprime? E não é preciso perguntar-se se o trabalho sobre a forma não é o que torna possível a anamnese parcial de estruturas profundas, e recalcadas, se, em uma palavra, o escritor mais preocupado com a pesquisa formal - como Flaubert e tantos outros depois dele - não é levado a agir como médium das estruturas (sociais ou psicológicas) que chegam à objetivação, através dele e de seu trabalho (Bourdieu, 1996, p. 17-18).

O reconhecimento do potencial político e gnosiológico da arte é de extrema importância - afinal, o vínculo entre arte, conhecimento e crítica permitiria ultrapassar o suposto monopólio da reflexividade/crítica sociológica - e se manifesta na declarada intenção bourdieusiana de instaurar uma aliança entre artistas e cientistas por partilharem da condição comum de intelectuais.

A compreensão da arte como um discurso sobre o mundo é construída a partir da cisão entre o mundo da arte (marcado pela ausência de gravidade) e o mundo real (constituído pelas urgências e pela seriedade). A princípio, a oposição entre aparência estética e realidade implodiria a ponte que liga arte e realidade, gerando uma descontinuidade entre as experiências de ambos os universos. Todavia, para Bourdieu, a arte serve-se exatamente de seu afastamento em relação ao real para a ele se referir: o "encanto da obra literária deve-se [...] a que fale das coisas mais sérias sem pedir, à diferença da ciência, segundo Searle, para ser levada completamente a sério" (Bourdieu, 1996, p. 48). Graças ao caráter lúdico da arte, a linguagem artística seria capaz de falar a verdade acerca do mundo de uma forma que torna suportável aquilo que seria insuportável. É, então, possível, que a linguagem artística permita uma “compreensão denegatória, que não é uma compreensão pela metade" (Bourdieu, 1996, p. 49), construindo um 
discurso sobre o mundo de modo contraditório, produzindo "eufemismos da realidade", que "desvela velando", que "desrealiza e neutraliza a realidade" 7 .

Deve-se salientar que o caráter lúdico e "fictício" da arte não a torna inócua. Ao ser capaz de neutralizar e desrealizar a realidade, a obra de arte é dotada de um poder - historicamente possível por meio de uma cumplicidade entre produtores culturais e seu público em levar a arte a sério - de produzir um "efeito de realidade", que, para Bourdieu, é exatamente o poder de produzir a crença na realidade da arte. A consequência do deslocamento da seriedade do real para a seriedade da ficção é que, dessa forma, "uma referência denegada ao real [...] [permitiria] saber recusando saber o que ele é realmente" (Bourdieu, 1996, p. 49).

A obra de arte seria uma via de conhecimento histórico exatamente pelo fato de que a forma artística efetuaria uma objetivação das estruturas sociais e psicológicas, tornando possível uma "anamnese parcial de estruturas profundas, e recalcadas" (Bourdieu, 1996, p. 17-18). Diferentemente da ciência, que construiria um sistema de relações inteligíveis, racionais e conceituais (Bourdieu, 2015), a objetivação artística se daria através da expressão sensível, comunicando um saber à sensibilidade, não à razão. Por trás disso encontra-se a ideia segundo a qual a experiência da arte pode ser uma forma de conhecimento partilhado intersubjetivamente, à semelhança do proposto por Gadamer (2014). Inclusive, Bourdieu reconhecia explicitamente o fato de que arte e ciência seriam formas de conhecimento, ainda que distintas, tanto que afirma:

Não há melhor atestado de tudo que separa a escrita literária da escrita científica do que essa capacidade, que ela possui exclusivamente, de concentrar e de condensar na singularidade de uma figura sensível e de uma aventura individual [...] toda a complexidade de uma estrutura e de uma história que a análise científica precisa desdobrar e estender laboriosamente. (Bourdieu, 1996, p. 39).

${ }^{7} \mathrm{O}$ poder de neutralização do real - isto é, do arbitrário cultural e do poder simbólico a ele associado - mediante uma ruptura com a seriedade, não é monopólio da disposição estética, podendo ser rastreado no humor (Cf. Berger, 1997). 
Mas, enquanto o conhecimento sociológico pressupõe a ruptura epistemológica entre mundo prático e mundo teórico, bem como o esforço científico de construção teórica do objeto como meio de objetivação, a objetivação estética seria possível através do trabalho do artista sobre a forma - processo através do qual se realizaria uma tradução das estruturas do mundo em uma forma sensível. Não se trata de a arte relatar fatos, de descrever de modo fidedigno a suposta objetividade, imediata aos sentidos no mundo prático. Pelo contrário, Bourdieu afirma a autonomia da forma em relação à realidade - o que constitui a liberdade estética -, transcendendo a função representacional da arte e apontando para uma prática construtiva ${ }^{8}$. Ao abandonar a pretensão de cópia da realidade, a arte pode ultrapassar o reino da aparência (a objetividade imediata do mundo prático) e alcançar a essência (as estruturas profundas, não conscientes). Paradoxalmente, a autonomia dos princípios de construção artísticos conduz a um retorno inesperado do real no mundo da arte ${ }^{9}$. Bourdieu (1996, p. 116) afirma, em relação à literatura, que a escrita artística tem como finalidade "nada menos que escrever o real (e não de o descrever, de o imitar, de o deixar de alguma maneira produzir-se a si próprio, representação natural da natureza)". A forma estética transcende o mundo prático vulgar, permitindo uma experiência privilegiada da realidade, uma experiência intensificada, um acesso "ao real mais profundo, mais oculto" (Bourdieu, 1996, p. 49), ao "real mais real que aquele que se dá imediatamente aos sentidos e no qual se detêm os apaixonados ingênuos do real" (Bourdieu, 1996, p. 127).

A tese de que a arte efetiva uma objetivação de estruturas sociais e psicológicas através de uma tradução sensível torna-se plena de significado ao se reconhecer que, para Bourdieu, "o verdadeiro assunto da obra de

\footnotetext{
${ }^{8}$ Igualmente, o objeto científico é construído, não é redutível à realidade captada pelos sentidos. O vetor, para Bourdieu, seguindo Bachelard, vai do racional ao real, não o inverso. Há uma autonomia do objeto construído, exatamente devida ao papel central desempenhado pelo elemento racional.

${ }^{9}$ Semelhante à tese de Adorno (1970), segundo a qual a essência de uma verdadeira obra de arte é a sedimentação das contradições históricas, que reaparecem na obra e, então, permitem o acesso a seu conhecimento por meio da experiência estética.
} 
arte não é nada mais que a maneira propriamente artística de apreender o mundo, isto é, o próprio artista, sua maneira e seu estilo" (Bourdieu, 1996, p. 334). A forma é um ponto de vista sobre o social, o ponto de vista fornecido pelo artista. Se toda produção artística é marcada por uma "fórmula geradora", fórmula essa que seria produto das condições de existência do artista e que produziria um habitus aestheticus, isso significa que ele é um agente dotado de uma capacidade de objetivar o mundo, ou seja, de uma capacidade de reflexividade, de um conhecimento de si e do mundo.

A ascensão ao real mais profundo, mais oculto, mais verdadeiro, é exatamente o objetivo da própria reflexividade sociológica, que busca desvelar os determinantes inconscientes da vida social e subjetiva. Há uma proximidade entre arte e ciência, artista e cientista, exatamente pelo fato de ambos serem capazes de usufruírem de uma liberdade - concedida por dois campos intelectuais autonomizados - e produzirem conhecimentos, transcendendo a (in)consciência reinante na vida prática.

Percebe-se, então, que, em relação ao ofício do artista, Bourdieu reconhece tanto a possibilidade de práticas não deterministas quanto de ascensão à reflexividade. Cabe, agora, perguntar se o público, a partir de experiências estéticas, também pode ascender à reflexividade, isto é, é possível vincular gosto, liberdade e reflexividade?

\section{Gosto, liberdade e reflexividade: a experiência estética}

Dado o exposto, surge a inevitável pergunta: seguindo o argumento bourdieusiano de que há uma homologia entre o campo da produção e o campo da percepção, isto é, entre artista e público, é possível rastrear liberdade e reflexividade na experiência estética?

Paradoxalmente, embora Bourdieu reconheça no intelectual da dimensão estética a capacidade de, a partir de seu próprio ofício, usufruir da liberdade em relação ao arbitrário cultural, bem como usufruir da capacidade de objetivar o inconsciente histórico, isto é, o próprio habitus - a 
partir do qual se revela a ligação umbilical entre subjetividade e sociedade - o sociólogo francês não demonstra a mesma sensibilidade quando se trata do público. Seu olhar revela-se ambíguo e contraditório.

À primeira vista, a mais estranha contradição reside em sua própria taxonomia. Bourdieu (2011) produz uma tipologia dos gostos a partir de uma estratificação: o gosto elevado seria o gosto puro ${ }^{10}$, havendo ainda um gosto médio e um gosto popular. Em relação à forma pura do gosto homóloga aos princípios de visão e construção do artista puro - Bourdieu o define ora como "gosto de liberdade" (por ter como condição histórica de possibilidade a liberdade em relação às urgências e necessidades da vida), ora como "gosto da reflexão" (ligado a uma forma de prazer estético que transcende o sensorial, isto é, uma versão espiritualizada que rompe com a animalidade do mero sensorial). Todavia, em sua obra, há um silenciamento quanto à emergência de uma efetiva reflexividade a partir da experiência estética. Pode-se dizer, então, que há, em sua obra, uma relação robusta entre gosto puro e liberdade, mas há uma indeterminação quanto à possibilidade da reflexividade.

Quanto ao olhar puro, Bourdieu (2011, p. 12) afirma que ele “implica uma ruptura com a atitude habitual em relação ao mundo que, levando em consideração as condições de sua plena realização social, é uma ruptura social" e continua dizendo que ele "opera uma suspensão da adesão naïve que é a dimensão de uma relação quase lúdica com as necessidades do mundo". Ao conceber a disposição estética como uma forma de transgressão em relação à ordem social, Bourdieu reconhece a margem de liberdade conquistada pelo habitus dotado de tal princípio prático.

\footnotetext{
${ }^{10}$ Bourdieu reconhece a verdade e a validade da interpretação kantiana do gosto puro como uma fenomenologia da experiência estética (Cf. Bourdieu; Wacquant, 1992). O que Bourdieu busca resgatar são as condições históricas de possibilidade do gosto puro e quais seus limites. Sua maior crítica incide sobre o caráter não universal dessa experiência, considerando-a um privilégio social, mas que deve ser submetido à universalização, tal como aparece em seu manifesto "o corporativismo do universal", que busca universalizar as condições sociais de possibilidade de uma verdadeira liberdade em todas as esferas sociais.
} 
Embora reconheça a existência de "gostos de reflexão", Bourdieu não leva a cabo sua manifesta teorização a partir da experiência estética, mas por uma outra via: sua sociologia reflexiva. Há um argumento central em As regras da arte a partir do qual Bourdieu busca fundamentar a possibilidade de que sua sociologia reflexiva possua uma utilidade (uma reflexividade científica orientada para a conquista de maior liberdade estética) para o mundo da arte. Afinal, se o artista é um intelectual e encarna um dos modelos de crítica moderna, qual auxílio a sociologia poderia oferecer ao mundo da arte autônoma? Bourdieu insiste na possibilidade de que o conhecimento sociológico (uma experiência da obra mediada pelos instrumentos da ciência) implicaria não na redução ou destruição do prazer estético, mas, pelo contrário, amplificá-lo-ia. Bourdieu (1996, p.15) acredita que o conhecimento gerado por sua sociologia reflexiva das obras levaria o prazer estético a um patamar superior, estando a compreensão em condição de tornar o amor pela arte mais justificado e intenso: "o amor sensível pela obra pode realizar-se em uma espécie de amor intellectualis rei". Todavia, a tentativa de introduzir o vínculo entre a arte e o conhecimento através da razão teórica acabou por bloquear aquilo que o próprio Bourdieu atestava: a existência de gostos de reflexão independentes em relação à racionalidade reflexiva e passíveis de serem mobilizados pelos agentes no interior da dimensão estética.

À semelhança de Adorno (1970), que afirmava a necessidade de a experiência estética tornar-se filosófica, impondo limites à experiência da arte, Bourdieu, ao tentar fundamentar um sentido para a crítica e reflexividade sociológica na dimensão estética, acaba por silenciar sobre a possibilidade de que os agentes possam, independentemente do caminho por ele próprio traçado, alcançar uma reflexividade estética. Ainda que reconheça a margem de liberdade da disposição estética, bem como o viés crítico inscrito na forma estética, e até mesmo o acesso a um grau de consciência através da objetivação artística, Bourdieu sabota a si próprio, não desenvolvendo a reflexividade a partir da reconhecida existência dos "gostos de reflexão". 
Apesar disso, defendo que há elementos implícitos e latentes em sua obra que nos permitem ampliar a reflexão sobre a possibilidade de emergência de reflexividade a partir da experiência estética, na qual o gosto desempenha papel fundamental. A primeira, a partir de um esboço de uma teoria bourdieusiana do gosto; a segunda, pela lógica vulgar do gosto popular, que, embora seja associado à não liberdade, aponta para uma possível reflexividade.

Por "esboço de uma teoria do gosto", refiro-me à compreensão mais geral e abstrata de qual seja a lógica prático-estética do gosto. Para Bourdieu (2011), o gosto é um senso de orientação social, o princípio das escolhas subjetivas, dotado de uma lógica de funcionamento caracterizada por habilitar os agentes a identificarem tudo aquilo que lhes é mais adequado, mais bem ajustado. Por ser uma capacidade de captar semelhanças, simetrias, redundâncias, o gosto é o instrumento prático que permite construir os ajustes inconscientes entre subjetividade e objetividade (práticas sociais, objetos, espaços etc.). À semelhança do próprio habitus, o gosto é um "senso de homologia" com "tendência para generalização" (o gosto "emparelha e assemelha coisas e pessoas"), o que permitiria aos agentes reconhecerem nas práticas aparentemente as mais diversas uma equivalência estrutural, uma afinidade imediata entre presença e memória. É, então, um princípio de conformação do habitus ao mundo e do mundo ao habitus.

Há uma lógica identitária subjacente ao modo de funcionamento do gosto, como consta em seu texto A metamorfose dos gostos. O prazer do gosto estaria relacionado a uma experiência específica: ao encontro de duas histórias, quais sejam, a história objetivada na forma de obra de arte, por meio do trabalho artístico, e a história subjetivizada sob a forma de um habitus (Bourdieu, 2003). É o encontro entre estruturas semelhantes que desencadeia o prazer, mas sem que os agentes tenham plena consciência do fundamento histórico desse prazer estético, corroborando a visão mágica ignorante acerca de sua gênese social. O desprazer do gosto (pois o gosto é a capacidade de julgar mediante prazer e desprazer) proviria do desajuste ontológico-estrutural entre gosto (história subjetivada) e obra (história 
objetivada). Bourdieu (1996; 2011) converte o prazer estético kantiano de algo transcendental e universal em algo histórico e localizado. Apesar dessa tradução, mantém-se fiel a Kant e concebe o prazer estético como encontro harmonioso e inesperado entre estruturas mentais e estruturas objetivas, isto é, entre a história que se tornou sujeito e atua sob a forma do gosto e a história que se tornou objetiva através do ofício do artista. É o reencontro entre essas histórias - dotadas de uma homologia, simetria, equivalência - que fundamentaria a aparição do prazer estético. Afinal, uma vez que os agentes, a princípio, desconhecem o nexo histórico que as vincula, o reencontro entre ambas as histórias lhes aparece como algo inexplicável - o não-sei-quê da experiência estética.

Essa lógica identitária pressupõe um limiar entre reconhecimento e conhecimento a partir do qual se pode vislumbrar a possibilidade de acesso à reflexividade. O gosto é, para Bourdieu (2011), "uma forma elementar de conhecimento", qual seja, reconhecimento. Sem regras nem critérios explícitos, isto é, em estado prático, o gosto reconhece algo que já é conhecido, mas que não se sabe que sabe - para usar o argumento paradoxal de Agamben (1992). É um conhecimento que se pode alcançar pela via do reconhecimento, ainda que se mantenha submerso à consciência, mas à beira de sua emergência. É o próprio Bourdieu (2003, p. 171) quem diz, a respeito do gosto, que "descobrir uma coisa a seu gosto é descobrir-se, é descobrir o que se quer [...] o que se tinha a dizer e que não se sabia dizer, e que, por conseguinte, não se sabia". Ao reconhecer na objetividade algo em comum com a própria subjetividade (estruturalmente equivalente), o agente poderia ascender a uma forma de consciência e reflexividade propriamente estética. O prazer estético torna manifesto e aberto à consciência o fato de que há uma estrutura equivalente, homóloga, simétrica entre habitus e obra; o desprazer revela uma incongruência, à semelhança da hysteresis.

A experiência estética, então, pode ser concebida como uma via de ascensão desse conhecimento ainda não formulado explicitamente (exatamente pelo fato de a obra ser a objetivação de um habitus similar). Implicitamente, a partir da teoria bourdieusiana do gosto, é possível 
esboçar uma reflexividade por meio da experiência estética, afinal, o saber (conhecimento) ligado ao prazer (do reconhecimento) é o próprio desvelamento do nexo histórico entre as duas histórias que se encontram, isto é, o vínculo genético entre indivíduo e sociedade, entre um habitus produzido e o mundo que o produziu. O prazer/desprazer do gosto permite um conhecimento tanto subjetivo quanto objetivo, referente tanto ao habitus quanto à vida social. Se a linguagem artística é definida pela capacidade de o artista exprimir aquilo que não pode ser plenamente conhecido senão pela linguagem sensível, a experiência estética deveria ser concebida como uma forma de conhecimento na qual, através do reconhecimento do gosto, poder-se-ia ampliar o conhecimento acerca da ligação umbilical entre as estruturas de personalidade e as estruturas sociais, isto é, um saber que rompe o inconsciente histórico, balizado pelo prazer (proveniente da identidade entre gosto e obra) e pelo desprazer (oriundo da alteridade entre ambos).

O gosto popular, ironicamente, apesar de ser associado à não liberdade e não ser concebido por Bourdieu como um "gosto de reflexão", a partir de sua lógica, poderia conduzir à reflexividade. A característica principal do gosto popular é a instituição da identidade entre mundo da arte e mundo da vida ${ }^{11}$, haja vista que, para Bourdieu (2011), o gosto popular não é verdadeiramente estético, mas sim pragmático, funcionalista, utilitário, impondo uma necessidade essencial à arte: significar algo. $\mathrm{O}$ gosto popular contradiz a autonomia estética. Todavia, é exatamente por impor a necessidade da significação que a estética popular pode ser pensada como via de acesso à reflexividade. Ao aplicar no mundo da arte os princípios práticos do mundo da vida, exigindo que a arte tenha um elo com a realidade, ter-se-ia como consequência o fato de que os agentes, não sabendo levar a arte segundo a disposição pura, consideremna segundo princípios de percepção e apreciação da própria realidade objetiva. O gosto popular exige que a arte faça sentido, que ela signifique algo, que estabeleça uma comunicação com a realidade. Por mais impura que seja do ponto de vista estético e cultural, por mais vulgar que seja ${ }^{11}$ Próxima à formulação proposta em A desumanização da arte por Ortega y Gasset (2001). 
a identidade instituída entre arte e realidade, o gosto popular, incapaz de se afastar da seriedade e da urgência, acaba por levar a indistinção entre arte e realidade a um ponto cuja implicação torna-se política. O fato é que, recusando percebê-las como esferas distintas e autônomas, a experiência estética funcionaria como uma extensão da realidade, tendo, como consequência, que toda divergência entre realidade e arte venha a se tornar uma contradição radical: ou seja, fundamento básico para uma reflexão. Assim, por mais que se questione e condene o gosto popular, seu modo de funcionamento conduz a uma considerável probabilidade de gerar uma reflexividade, exatamente por levar a arte demasiadamente a sério e segundo os parâmetros do arbitrário cultural.

\section{Considerações finais}

A persistência do pensar Bourdieu com Bourdieu e mesmo contra Bourdieu revela que mesmo o autor não se tornou imune às más consequências de uma (inevitável) reflexividade parcial. O esforço de se pensar novas vias para a liberdade e a reflexividade em seu pensamento, centralizando a dimensão estética, abriu novas perspectivas, mas também revelou novos limites, contradições e problemas. Quanto a isso, percebese que a reflexividade sociológica se desenvolve na prática como uma aquisição coletiva.

O empreendimento de lançar um olhar pouco convencional à obra de Bourdieu, estabelecendo um diálogo mais próximo com as questões da própria estética, revela-se produtiva na medida em que permite pensar mais e melhor, isto é, enriquecer as discussões em torno de sua teoria, bem como de suas análises.

Amarildo Malvezzi é Doutor em Sociologia pela Universidade Federal de Pernambuco e desenvolve pesquisas nas áreas de teoria sociológica, sociologia da cultura e estética.

”imalvezzi@gmail.com 


\section{Referências}

1. ADORNO, Theodor. Teoria estética. Lisboa: Edições 70, 1970.

2. ADORNO, Theodor; HORKHEIMER, Max. Dialética do esclarecimento: fragmentos filosóficos. Rio de Janeiro: Jorge Zahar, 1985.

3. ADORNO, Theodor. Notas sobre literatura I. São Paulo: Duas Cidades, 2003.

4. AGAMBEN, Giorgio. Gosto. In: Enciclopédia Einaudi, v. 25. Criatividade Visão. Portugal: Imprensa Nacional/Casa da Moeda, 1992.

5. ALEXANDER, Jeffrey. The reality of reduction: the failed synthesis of Pierre Bourdieu. In: ALEXANDER. Fin de siècle social theory: relativism, reduction and the problem of reason. Londres; Nova York: Verso, 1995.

6. BERGER, Peter. Redeeming laughter: the comic dimension of human experience. Berlim; Nova York: Walter De Gruyter, 1997.

7. BOLTANSKI, Luc. On critique: a sociology of emancipation. Cambridge: Polity Press, 2011.

8. BOURDIEU, Pierre. As regras da arte: gênese e estrutura do campo literário. São Paulo: Companhia das Letras, 1996.

9. BOURDIEU, Pierre. Meditações pascalianas. Rio de Janeiro: Bertrand Brasil, 2001.

10. BOURDIEU, Pierre. Questões de sociologia. Lisboa: Fim de Século, 2003.

11. BOURDIEU, Pierre. A distinção: crítica social do julgamento. Porto Alegre: Zouk, 2011.

12. BOURDIEU, Pierre. Outline of a theory of practice. Nova York: Cambridge University Press, 2013.

13. BOURDIEU, Pierre et al. Ofício de sociólogo: metodologia da pesquisa na sociologia. Petrópolis: Vozes, 2015.

14. BOURDIEU, Pierre ; WACQUANT, LoÏc. An invitation to reflexive sociology. Chicago: University of Chicago Press, 1992.

15. DANTO, Arthur. O abuso da beleza: a estética e o conceito de arte. São Paulo: Editora WMF Martins Fontes, 2015.

16. EAGLETON, Terry. A ideologia da estética. Rio de Janeiro: Zahar, 1993.

17. FERRY, Luc. Homo aestheticus: a invenção do gosto na era democrática. São Paulo: Ensaio, 1994.

18. GADAMER, Hans-George. Verdade e método: traços fundamentais de uma hermenêutica filosófica. V. 1. Petrópolis, RJ: Vozes, 2014.

19. HILGERS, Mathieu. Habitus, freedom, and reflexivity. Theory \& Psychology., v. 19, n. 6, p. 728-755, 2009. doi: 10.1177/0959354309345892 
20. JENKINS, Richard. Pierre Bourdieu and the reproduction of determinism. Sociology, v. 16, n. 2, p. 270-281, 1982. doi: 10.1177/0038038582016002008

21. KNAFO, Samuel. Bourdieu and the dead end of reflexivity: on the impossible task of locating the subject. Review of International Studies, v. 42, n. 1, p. 25-47, 2016. doi: 10.1017/S0260210515000121

22. OLSON, Kevin. Habitus and body language: towards a critical theory of symbolic power. Philosophy \& Social Criticism, v. 21, n. 2, p. 23-49, 1995. doi: 10.1177/019145379502100202

23. ORTEGA Y GASSET, Jose. A desumanização da arte. São Paulo: Cortez, 2001.

24. PETERS, Gabriel. Habitus, reflexividade e neo-objetivismo na teoria da prática de Pierre Bourdieu. Revista Brasileira de Ciências Sociais, São Paulo, v. 28, n. 83, p. 47-71, 2013. doi: 10.1590/S0102-69092013000300004

25. WACQUANT, LoÏc. Durkheim and Bourdieu: the common plinth and its cracks. In: SUSEN, Simon; Turner, BRYAN S. The legacy of Pierre Bourdieu: critical essays. Org. Simon Susen e Bryan S. Turner. New York: Anthem Press, 2011. 